\title{
Cannulating LIMA Graft Using Right Transradial Approach: Two Simple and Innovative Techniques
}

\author{
Tejas Patel, ${ }^{1,2^{\star}}$ MD, FACC, FSCAI, Sanjay Shah, ${ }^{1,2}$ MD, and Tejan Patel, ${ }^{3}$ MD, FACC, FSCAI \\ Angiography and intervention of a LIMA (left internal mammary artery) graft cannot be \\ performed easily while working through right transradial approach (TRA), because of \\ complexity in anatomical relations of right and left subclavian arteries with arch of \\ aorta. We demonstrate two simple and innovative techniques for the same using right \\ TRA. (c) 2012 Wiley Periodicals, Inc.
}

Key words: LIMA graft cannulation; right transradial approach; transradial intervention

\section{INTRODUCTION}

Transradial approach (TRA) is becoming increasingly popular for performing both coronary and noncoronary angiography and interventions [1-5]. Bypass graft angiography and intervention are also done using both right and left TRA [1-7]. However, right TRA is commonly selected because of the comfort level of operator and supportive staff [1-7]. For cannulating LIMA graft left TRA offers easier and faster cannulation because of simple anatomical relationship [6-8]. With increasing use of left radial artery (RA) as a bypass graft conduit, many times left TRA is not possible for the procedure of LIMA graft. Hence, adequate technical knowledge of LIMA cannulation through right TRA is essential for all the radial operators.

\section{CASE REPORT}

\section{Case-1}

A 65-year-old man presented to our institute with unstable angina. He gave history of hypertension since 12 years, diabetes since 10 years, and dyslipidemia since 7 years. He had undergone coronary artery bypass graft surgery before 10 years and received LIMA graft to LAD, saphenous vein graft (SVG) to distal RCA and RA graft to major OM artery. Left RA was used as a bypass conduit. After optimal medical management he was subjected to coronary angiography with bypass graft evaluation using right TRA. We evaluated native coronary arteries and SVG as well as RA graft in usual fashion working through right TRA. Then, we cannulated origin of left subclavian artery using a 5F Optitorque TIG diagnostic catheter (Terumo, Japan) and a 0.035" standard exchange length guidewire was advanced through subclavian artery into brachial artery (Fig. 1A and B). Then, the catheter was removed and a 5F IMA diagnostic catheter (Cordis, Johnson and Johnson) was advanced over the same wire. However, catheter and guidewire had tendency to flip in ascending aorta while trying to negotiate further in left subclavian artery (Fig. 1C). This happened because of instability created by complex anatomical angles of both subclavian arteries with aortic arch. We decided to tie a BP cuff on left arm and inflated it significantly above systolic BP of the patient (i.e., $180 \mathrm{~mm} \mathrm{Hg}$ ). By doing this, we could successfully trap the guidewire in brachial artery (Fig. 1D). Then, we could easily advance the catheter over-the-wire in left subclavian artery distal to the origin of LIMA (Fig. 1E). We succeeded because trapped guidewire gave additional support to the catheter. We deflated the BP cuff and removed the guidewire. We cannulated LIMA with IMA catheter by slight pull-back and counter-clock rotation to complete LIMA angiogram (Fig. 1F).

\footnotetext{
${ }^{1}$ Total Cardiovascular Solutions Private Limited, Ahmedabad, India

${ }^{2}$ Department of Cardiology, Sheth V.S. General Hospital and Smt. N.H.L. Municipal, Medical College, Ahmedabad 380 006, India

${ }^{3}$ Department of Interventional Cardiology, Unity Health System, Rochester, New York
}

Conflict of interest: Nothing to report.

*Correspondence to: Tejas Patel, MD, FACC, FSCAI, Professor and Head, Department of Cardiology, Sheth V.S. General Hospital and Smt. N.H.L. Municipal, Medical College, Ahmedabad-380 006, India

Received 11 December 2011; Revision accepted 7 January 2012

DOI $10.1002 / \mathrm{ccd} .24321$

Published online 2 May 2012 in Wiley Online Library (wileyonlinelibrary.com) 

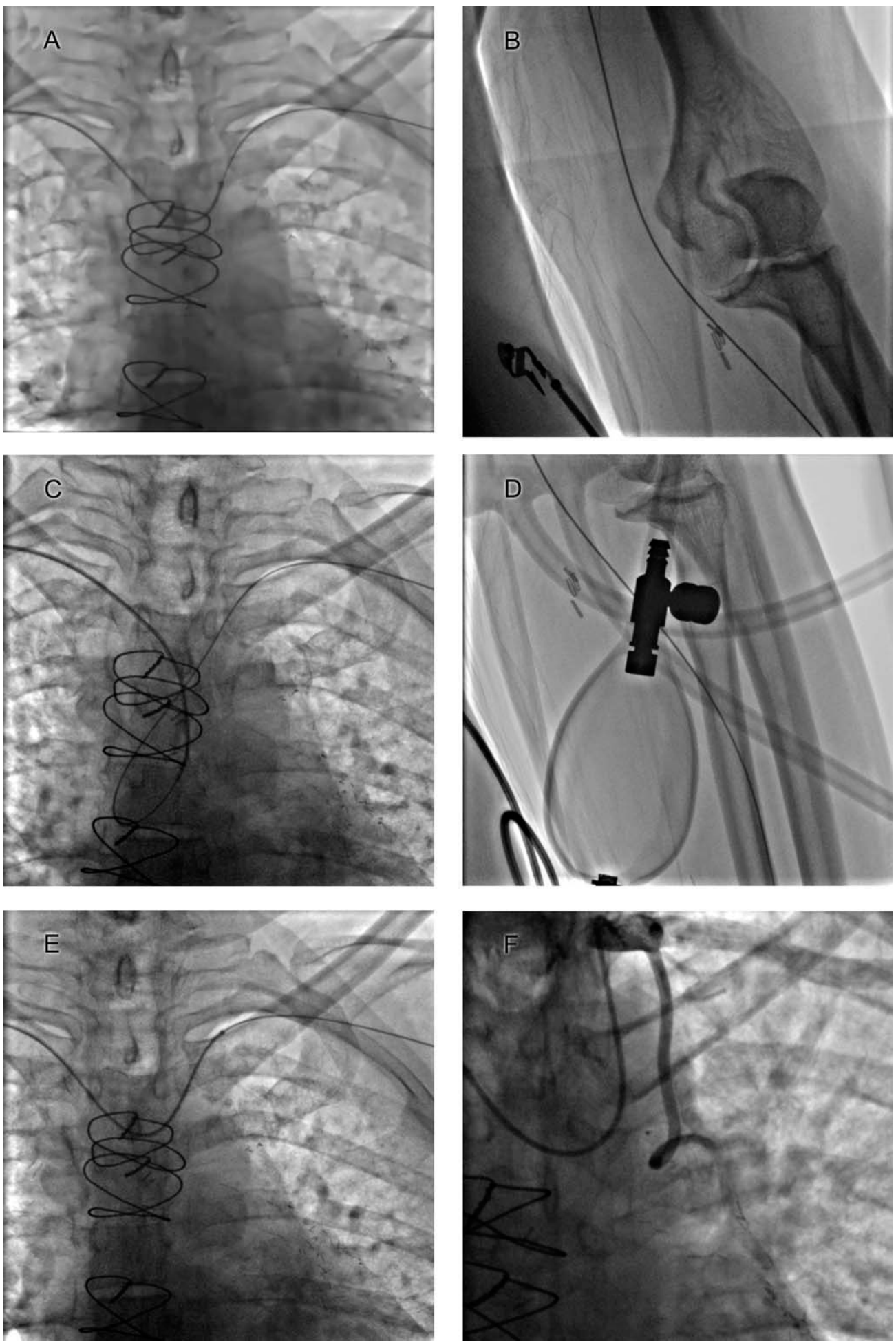

Fig. 1. A and B: Cannulation of origin of left subclavian artery using a 5F Optitorque TIG diagnostic catheter (Terumo, Japan) and advancement of a $0.035^{\prime \prime}$ standard exchange length guidewire into left brachial artery; C: Tendency to flip in ascending aorta; D: The guidewire was trapped in left brachial artery by inflating BP cuff at $180 \mathrm{~mm} \mathrm{Hg}$; E: The catheter was negotiated and placed in left subclavian artery distal to LIMA origin; and F: LIMA angiogram was done. 

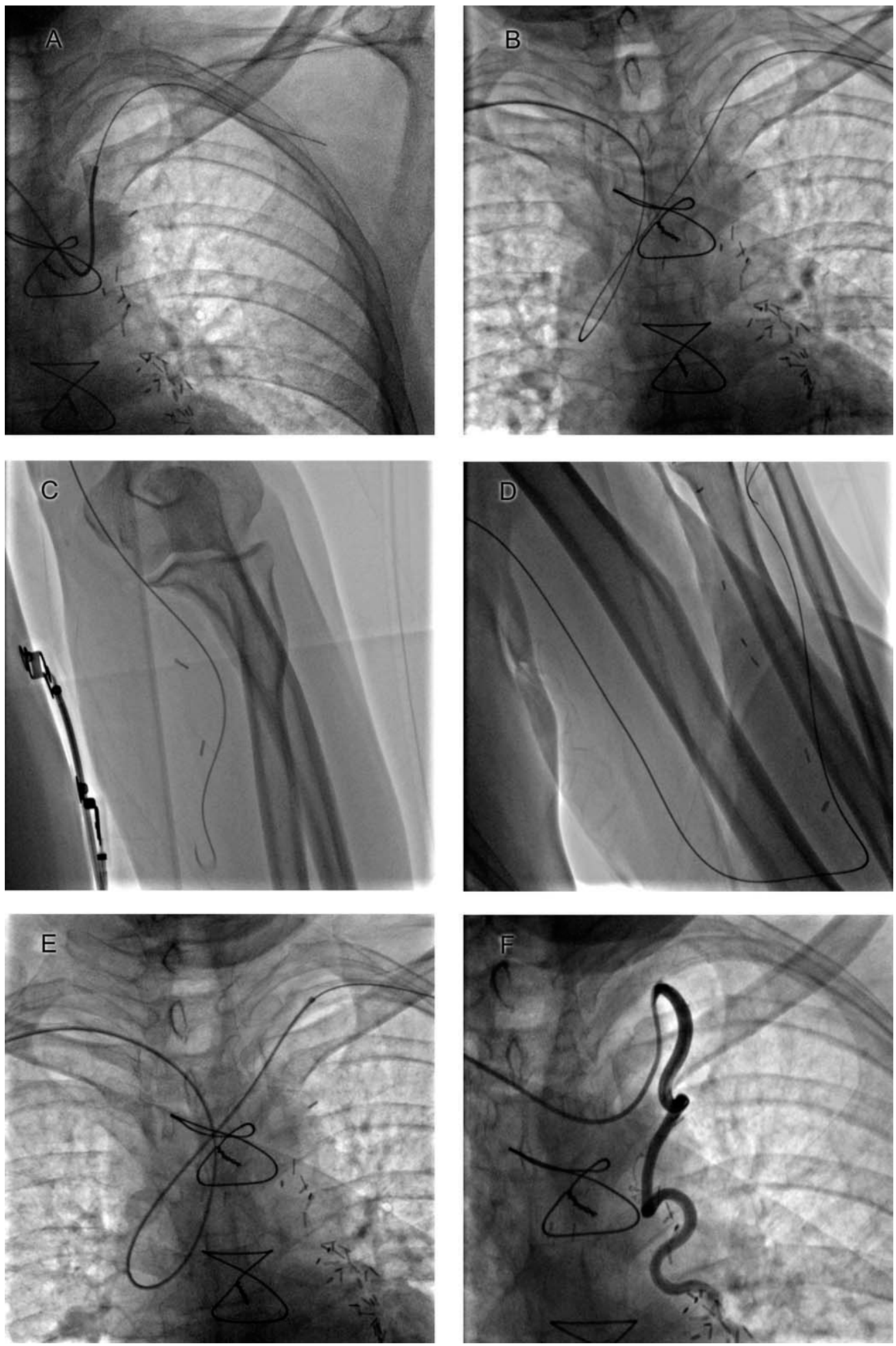

Fig. 2. A: 5F Simons-1 catheter cannulated origin of left subclavian artery; B: The assembly flipped in ascending aorta; C: A $0.032^{\prime \prime}$ exchange length hydrophilic guidewire was placed in left ulnar artery; D: Left elbow joint flexion adequately trapped the guidewire to give additional support; E: IMA (internal mammary artery) catheter was negotiated into subclavian artery beyond origin of LIMA; and F: LIMA angiogram was done. 

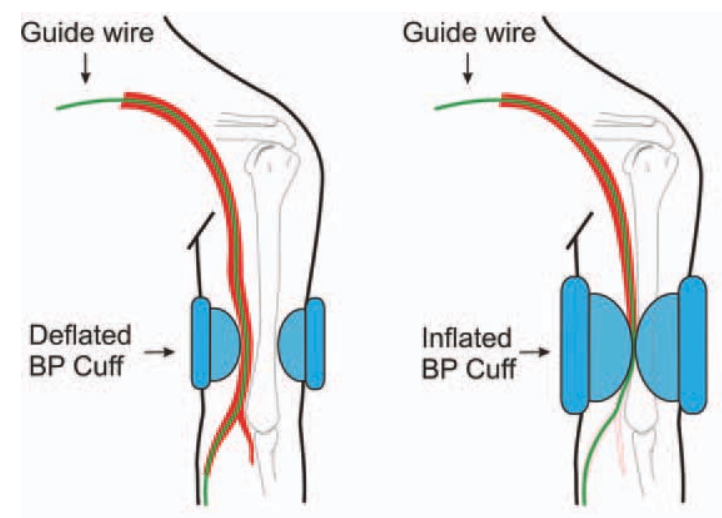

\section{(A). BP CUFF TECHNIQUE}

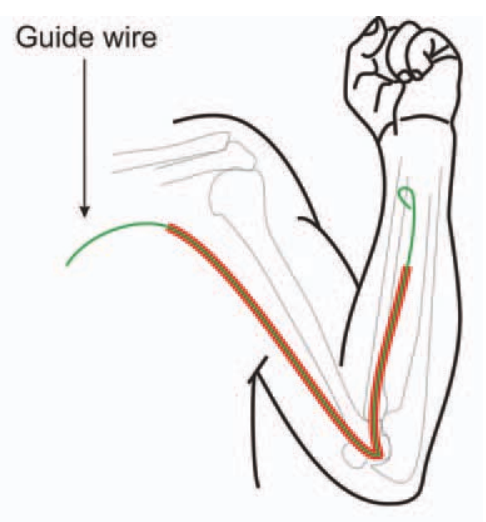

(B). ELBOW FLEXION TECHNIQUE

Fig. 3. A and B: Schematic representation of both the techniques. [Color figure can be viewed in the online issue, which is available at wileyonlinelibrary.com.]

\section{Case-2}

A 72-year-old diabetic hypertensive male patient with past history of CABG surgery done before 10 years presented to us with unstable angina. During bypass graft evaluation, for cannulating LIMA graft we used a 5F Simons-1 catheter (Cordis, Johnson \& Johnson) and a standard $0.035^{\prime \prime}$ exchange length guidewire. We cannulated origin of left subclavian artery (Fig. 2A). However, while negotiating the guidewire, there was tendency for the assembly to flip in ascending aorta (Fig. 2B). We removed the standard guidewire and replaced it with a $0.032^{\prime \prime}$ exchange length hydrophilic guidewire (Glidewire, Terumo, Japan) which could easily be negotiated through subclavian artery and brachial artery into ulnar artery (Fig. 2C). We tied the BP cuff and inflated it above systolic pressure (i.e., $200 \mathrm{~mm} \mathrm{Hg}$ ) to trap the guidewire and negotiated the catheter over-the-wire. However, the whole assembly had tendency to flip in ascending aorta. Because of hydrophilic nature of guidewire, it could not be trapped by this technique. Hence, we deflated the BP cuff and removed it. We asked the patient to flex his left elbow joint (Fig. 2D). By doing this, we trapped the hydrophilic guidewire to get enough support for exchanging Simon-1 catheter to IMA catheter. It was then negotiated into subclavian artery beyond origin of LIMA (Fig. 2E). The guidewire was then removed and LIMA cannulation was then performed in usual fashion (Fig. 2F).

\section{DISCUSSION}

Cannulating LIMA graft using right TRA is at times challenging because of complex angles of both subclavian arteries in relation to arch of aorta [6-11]. Sometimes, tortuosity of right subclavian artery adds to the complexity [10-12]. This can lead to difficulty for achieving stable position of a guidewire and/or a catheter (IMA catheter or Optitorque Tig catheter - Terumo, Japan) in left subclavian artery. We regularly perform LIMA cannulation using right TRA. At times, if the anatomy is favorable, with relatively smooth angles of subclavian arteries in relation to arch, IMA or Optitorque Tig catheter can easily be negotiated in left subclavian artery to cannulate LIMA. Not uncommonly, an operator struggles for entry in left subclavian artery as there is tendency of the assembly to flip in ascending aorta despite parking a guidewire tip deep in left brachial, ulnar for RA. Both the techniques described by us demonstrate reliable trapping of a guidewire either in brachial artery using a BP cuff or at flexed elbow joint giving additional support for a catheter to be negotiated easily in left subclavian artery (Fig. 3A and B). A standard guidewire without hydrophilic coating can be predictably trapped by BP cuff technique. However, it may not work all the time particularly when hydrophilic wire is used. For trapping hydrophilic guidewire, elbow flexion seems to be a better technique. Once the catheter sits in left subclavian artery beyond origin of LIMA, a gentle pull back should easily cannulate LIMA. In past, we have used the BP cuff successfully to trap a diagnostic catheter to reduce a complex knot in it [13].

To conclude, both techniques are simple and easy to practice and may help an operator to work successfully in this type of demanding situations working through right TRA.

\section{ACKNOWLEDGEMENTS}

Authors are grateful to Mr. Yash Soni and Mr. Chidambaram Iyer for their extremely valuable support during preparation of this manuscript. 


\section{REFERENCES}

1. Rao S, Cohen M, Kandzari D, et al. The transradial approach to percutaneous coronary intervention : historical perspective, current concepts, and future directions. J Am Coll Cardiol 2010; 55:2187-2195.

2. Kern M. The rising tide of transradial cardiac catheterization: Riding the wave. J Invasive Cardiol 2011;23:93-94.

3. Gilchrist I. Transradial catheterization's grass roots epidemic. JACC Cardiovasc Interv 2010;3:1032-1034.

4. Caputo RP, Tremmel JA, Rao S, et al. Transradial arterial access for coronary and peripheral procedures: Executive summary by the transradial committee of the SCAI. Catheter Cardiovasc Interv 2011;78:823-839.

5. Patel T. Shah S, Ranjan A. Patel's Atlas of Transradial Intervention: The Basics. Seattle, Washington: Sea Script Company; 2007.

6. Burzotta F, Trani C, Hamon M, et al. Transradial approach for coronary angiography and interventions in patients with coronary bypass grafts: Tips and tricks. Catheter Cardiovasc Interv 2008;72:263-272.

7. Cha K, Kim M. Feasibility and safety of concomitant left internal mammary arteriography at the setting of the right transradial coronary angiography. Catheter Cardiovasc Interv 2002;56:188195.

8. Kim M, Cha K, Kim H, et al. Bilateral selective internal mammary artery angiography via right radial approach : clinical experience with newly designed Yumiko catheter. Catheter Cardiovasc Interv 2001;54:19-24.

9. Gilchrist I. Transradial technical tips. Catheter Cardiovasc Interv 2000;49:353-354.

10. Dehghani P, Mohammad A, Bajaj R, et al. Mechanism and predictors of failed transradial approach for percutaneous coronary interventions. JACC Cardiovasc Interv 2009;2:1057-1064.

11. Valsecchi O, Vassileva A, Musumeci G, et al. Failure of transradial approach during coronary interventions: Anatomic considerations. Catheter Cardiovasc Interv 2006;67:870-878.

12. Cha K, Kim M, Kim H. Prevalence and clinical predictors of severe tortuosity of right subclavian artery in patients undergoing transradial coronary angiography. Am J Cardiol 2003;92:12201222.

13. Patel T, Shah S, Pancholy S. A simple approach for the reduction of knotted coronary catheter in the radial artery during the transradial approach. J Invasive Cardiol 2011;23:E126-E127. 